\title{
El destino de la sociedad conyugal
}

Este comentario, junto a los documentos que analiza, está disponible en www.anuariocdh.uchile.cl

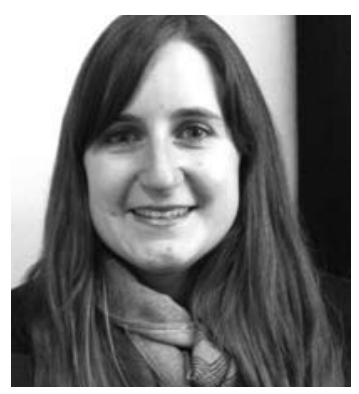

\begin{abstract}
María Paz Gatica R.
Abogada, Licenciada en Ciencias Jurídicas y Sociales. Profesora de Derecho Civil, Facultad de Derecho, Universidad de Chile.

mgatica@derecho.uchile.cl
\end{abstract}

\section{RESUMEN}

El régimen chileno de sociedad conyugal establece distinciones legales que resultan discriminatorias para ambos cónyuges. En el caso de la mujer, al impedir que pueda ser administradora ordinaria de los bienes sociales y privarla de la administración de sus bienes propios, y en el del marido, a través de la institución del patrimonio reservado. En este artículo se revisan los problemas recientes que dicho régimen ha generado para el Estado de Chile en el contexto internacional y se analizan algunas de las propuestas de reforma legislativa desde la perspectiva de su cumplimiento con los estándares de derechos fundamentales.

\section{Introducción al régimen chileno de sociedad conyugal}

La legislación chilena ofrece a los cónyuges tres alternativas de regulación patrimonial del matrimonio: el régimen de sociedad conyugal, el de participación en los gananciales -en su variante crediticia $^{1}$ - y el de separación total de bienes. Ante el silencio de los cónyuges, el régimen supletorio es el de sociedad conyugal.

El régimen de sociedad conyugal nació conjuntamente con nuestro Código Civil. A la época de su dictación -1855- era el único régimen existente ${ }^{2}$ y constituía el claro reflejo del modelo de familia imperante y de los principios que inspiraban el derecho de familia: un modelo patriarcal

1 En el régimen de participación en los gananciales, en su variante crediticia, los cónyuges actúan como separados durante la vigencia del régimen. A su término, se comparan las ganancias obtenidas por los cónyuges, surgiendo un crédito a favor de aquel que obtuvo menos ganancias en contra del que ganó más, por un monto igual a la mitad del exceso de ganancias del segundo por sobre el primero. De este modo, los cónyuges queda equiparados en las ganancias. Esta variante se opone a la denominada "de comunidad diferida", en que al término del régimen no surge un crédito, sino una comunidad entre los cónyuges sobre las ganancias de ambos, que debe someterse a un procedimiento de partición.

2 Los otros dos regímenes patrimoniales surgieron posteriormente: el de separación total de bienes en el año 1925 (D. L. 328 de 1925) y el de participación en los gananciales recién en el año 1994 (Ley № 19.335). 
en que el marido es el proveedor del grupo familiar y la mujer -incapaz relativa- asume la labor del cuidado de los hijos y del hogar común.

Ello explica en gran medida la configuración del régimen en cuestión que, si bien ha sufrido sucesivas modificaciones, no ha perdido sus características esenciales, que se describen brevemente en las líneas que siguen ${ }^{3}$.

Desde el punto de vista de su titularidad, el régimen de sociedad conyugal reconoce dos clases de bienes: los sociales y los propios de cada cónyuge.

El patrimonio social se compone de dos partidas: el haber absoluto -al cual ingresan los bienes de manera definitiva y corresponden a los cónyuges por partes iguales al momento de la liquidación del régimen-y el haber relativo -al cual ingresan los bienes de manera "temporal", en el sentido de que generan un derecho para el cónyuge que los aporta a ser recompensado al momento de terminar el régimen. A grandes rasgos, el haber absoluto se compone de todos los bienes que los cónyuges adquieran a título oneroso durante la vigencia del régimen, mientras que el relativo está constituido por los bienes de naturaleza mueble que los cónyuges aportan al matrimonio -se encontraban en su patrimonio al momento de contraerlo- o adquieren a título gratuito durante la vigencia del régimen.

El patrimonio propio de cada cónyuge, por su parte, contiene, principalmente, los bienes inmuebles de su propiedad al momento de contraer matrimonio y aquellos que adquiere a título gratuito durante la vigencia del régimen (por ejemplo, los inmuebles heredados), sin perjuicio de otros bienes particulares que sean excluidos del patrimonio social por voluntad de los mismos cónyuges. Estos bienes permanecen en el patrimonio de su dueño tanto durante la vigencia del régimen, como al momento de su término.

Ahora, desde el punto de vista de su administración, la cuestión es bastante más simple: el marido es el "jefe" de la sociedad conyugal y en tal calidad administra ordinariamente no sólo los bienes sociales, sino también los propios de la mujer -pese a ser ella plenamente capaz-, sujeto sin embargo a una serie de limitaciones que le ordenan obtener la autorización de la mujer para realizar varios de los actos jurídicos de mayor trascendencia económica ${ }^{4}$.

La gran excepción a esta regla de administración está constituida por la institución del patrimonio reservado de la mujer casada: la mujer que realiza un trabajo remunerado, separado del de su marido, tiene la facultad de administrar, libremente y sin limitaciones, los bienes que obtenga con el fruto de dicho trabajo ${ }^{5}$. La alteración se produce sólo desde el punto de vista de la administración de estos bienes, pues desde la perspectiva de su titularidad, se trata de bienes sociales, pertenecientes al haber absoluto. Por tanto, al término del régimen, en principio, ingresan a la división. Y decimos en principio, pues la ley otorga a la mujer un derecho a optar entre compartir este patrimonio con su marido -ingresa a la masa común, dividiéndose tanto bienes como deudas- o conservar para sí este patrimonio, conservando el marido, por su parte, todos los demás bienes y deudas sociales. Ésta es la denominada "facultad de aceptar o renunciar a los gananciales".

\footnotetext{
3 Para una descripción completa del régimen, véase RAMOS PAZOS, René. Derecho de Familia. Santiago, Editorial Jurídica de Chile, 2010. $7^{\mathrm{a}}$ ed. actualizada. Tomo I.

Artículo 1749 del Código Civil.

5 Artículo 150 del Código Civil.
} 


\section{La sociedad conyugal ante la Comisión Interamericana de Derechos Humanos}

En el año 2007, se le dio "suma urgencia" 6 a la tramitación del proyecto de ley de reforma al sistema chileno de regímenes patrimoniales del matrimonio ${ }^{7}$, lo que se tradujo en una renovada atención académica y política a la materia. Esta decisión estuvo motivada por el compromiso que asumió el Estado de Chile ante la Comisión Interamericana de Derechos Humanos ${ }^{8}$, como parte de la solución amistosa alcanzada en el caso "Sonia Arce Esparza con Chile" ${ }^{9}$.

El caso se refiere a una mujer casada bajo el régimen de sociedad conyugal cuya intención de enajenar ciertos bienes inmuebles que había heredado -y que, por tanto, formaban parte de su patrimonio propio- se vio frustrada por no contar con la autorización de su marido, quien se encontraba imposible de localizar a la fecha. La solicitante sostuvo que las reglas de administración de la sociedad conyugal atentaban contra los derechos consagrados en los tratados internacionales sobre derechos humanos, particularmente la igualdad ante la ley, y que solicitar una autorización judicial subsidiaria a la voluntad del marido para poder enajenar los bienes ${ }^{10}$ significaba precisamente someterse a esa discriminación.

En la solución amistosa alcanzada en el caso, el Estado de Chile se comprometió a realizar una serie de acciones destinadas a "poner término a la discriminación legal implícita en el régimen de sociedad conyugal"11.

La fórmula general de este compromiso resulta particularmente relevante, pues no sólo requería esfuerzos por resolver el problema de la administración de los bienes propios de la mujer casada bajo el señalado régimen -que fue precisamente el que dio origen al caso ante la Comisión-, sino también las dificultades relativas a la administración de los bienes sociales. En otras palabras, para cumplir la exigencia de poner término a la discriminación legal implícita en el régimen de sociedad conyugal se hacía necesaria una reforma integral del mismo.

Pese al compromiso asumido por el Estado, la tramitación del proyecto volvió a caer en la inactividad. La preocupación de la Comisión ante esta pasividad se hizo presente en marzo del año 2009, cuando recomendó "[i]ncrementar la colaboración entre el Poder Ejecutivo y Legislativo para agilizar la aprobación del proyecto de ley encaminado a reformar el régimen vigente de sociedad conyugal"12.

6 Conforme al Artículo 26 de la Ley Orgánica Constitucional del Congreso Nacional (Ley № 18.918), el Presidente de la República puede hacer presente la urgencia para el despacho de un proyecto de ley. Esta urgencia puede ser simple, suma o de discusión inmediata, calificación que incide en los plazos que se fija a la respectiva Cámara para la discusión y votación del proyecto. Estos plazos fueron objeto de una reciente modificación (Ley № 20.447 de 3 de julio de 2010), pero a la época en que se hizo presente para el proyecto en comento, el plazo en el caso de la suma urgencia era de 10 días. Luego de la modificación, se amplió a 15 días.

7 BOLETíN 1707-18. Modifica el Código Civil y leyes complementarias en materia de sociedad conyugal o comunidad de gananciales, otorgando a la mujer y al marido iguales derechos y obligaciones. Fecha de ingreso: 4 de octubre de 1995. [en línea] <http://sil.congreso.cl/pags/index.html> [consulta: 10 diciembre 2010]

8 En adelante, la Comisión.

9 ACUERDO DE SOlUCIÓN AMISTOSA, Caso No 12.433 Sonia Arce Esparza v. Chile. Diario Oficial, 3 de mayo de 2008. Santiago, Chile.

10 En caso de ausencia del marido, el artículo 138 del Código Civil faculta a la mujer para administrar sus bienes propios bajo dos supuestos: si la ausencia es prolongada, solicitando al juez la administración extraordinaria de la sociedad conyugal; si no tiene tal carácter, solicitando al juez una autorización subsidiaria a la voluntad del marido para realizar algún acto de administración sobre un bien determinado.

11 ACUERDO DE SOLUCIÓN AMISTOSA, op. cit., cláusula primera, letra a.

$12 \mathrm{CIDH}$, Informe sobre los derechos de las mujeres en Chile: la igualdad en la familia, el trabajo y la política. Documento 63. 27 de marzo de 2009. [en línea] <http://www.cidh.oas.org/countryrep/ChileMujer2009sp/Chilemujer09indice. sp.htm> [consulta: 23 enero 2011] 
No es la primera vez que se presenta un caso de esta naturaleza ante la Comisión. Ya en el año 1998 se había presentado una petición en la que se alegaba que ciertos artículos del Código Civil de Guatemala establecían distinciones discriminatorias entre hombres y mujeres. Se trataba de disposiciones que definían los papeles de los cónyuges dentro del matrimonio, prescribiendo que correspondía al marido la administración del patrimonio conyugal (artículo 131) y debía protección y asistencia a la mujer, mientras que a esta última correspondía la obligación de cuidar de los hijos y el hogar (artículo 110), facultándosela para ejercer un empleo sólo en la medida en que ello no perjudicara sus funciones de madre y ama de casa (artículo 113), pudiendo en todo caso el marido oponerse la realización de dicho empleo por razones justificadas (artículo 114), entre otras disposiciones.

La Comisión estimó que el Estado de Guatemala era responsable por la violación de los derechos fundamentales a la igual protección, respeto de la vida familiar y respeto por la vida privada de la peticionaria, recomendando adoptar las medidas legislativas necesarias para dejar sin efecto las disposiciones impugnadas, con el fin de hacer congruente la legislación nacional con las normas de la Convención Americana ${ }^{13}$.

En virtud de la recomendación citada, la legislación guatemalteca sufrió relevantes modificaciones. En lo relativo al tema que nos ocupa -régimen de bienes- se estableció un sistema de administración del patrimonio conyugal por ambos cónyuges, de manera conjunta o separada (artículo 131). Adicionalmente, se eliminaron algunas de las reglas tachadas de discriminatorias, como los artículos 113 y 114 citados. Sin embargo, la reforma no fue completa, subsistiendo, a modo de ejemplo, aquella regla que asigna al marido el deber de protección y asistencia respecto de su mujer, sin consagrar un deber análogo para la mujer respecto de su marido ${ }^{14}$.

El hecho de que la reforma a la legislación guatemalteca no fuese completa motivó a que la Comisión reiterara sus recomendaciones ${ }^{15}$, considerando que las obligaciones del Estado de Guatemala no se encontraban cumplidas mientras subsistiera alguna de las reglas discriminatorias descritas.

La decisión de la Comisión en el caso de Guatemala nos da algunas luces acerca de los estándares que nuestro proceso de reforma deberá cumplir: si el compromiso asumido en el acuerdo amistoso fue tomar todas las acciones necesarias para eliminar la discriminación contenida en el régimen, sin referirse a disposiciones o reglas específicas, la futura configuración de la sociedad conyugal deberá contemplar una regulación impecable desde el punto de vista de su conformidad con los derechos fundamentales del marido y de la mujer. De lo contrario, no se estimará cumplido el objetivo fijado por la Comisión.

Han transcurrido cuatro años desde que el Estado de Chile asumió este compromiso y nuestra legislación no ha sufrido ningún cambio: el proyecto de reforma al cual se refirió el acuerdo no registra movimientos desde el año 2008. La cuestión no es de una relevancia menor pues, pese a que los índices de adopción del régimen de sociedad conyugal han ido en descenso en los últimos años, sigue siendo el régimen mayoritario. De acuerdo a las estadísticas del Servicio de Registro Civil e Identificación, el 54,5\% de los matrimonios celebrados durante el año 2010 se sujetaron al régimen de sociedad conyugal, registrando el de separación de bienes una incidencia del 43,1\%,

13 COMISIÓN INTERAMERICANA DE DERECHOS HUMANOS, Informe No 4/01, Caso 11.625 María Eugenia Morales de Sierra v. Guatemala. 19 de enero de 2001. [en línea] <http://www.cidh.oas.org/women/Guatemala11.625.htm> [consulta: 23 enero 2011] Párrafo No 55.

14 Ibíd, párrafo $\mathrm{N}^{\circ} 79$.

15 Ibíd, párrafo $\mathrm{N}^{\circ} 84$. 
y el de participación en los gananciales un $2,4 \%{ }^{16}$. Estos porcentajes se ven claramente influidos por la circunstancia de que la sociedad conyugal es el régimen supletorio.

En razón de las circunstancias expuestas, en el mes de octubre del año recién pasado, la Ministra del Servicio Nacional de la Mujer del actual Gobierno anunció la presentación de un nuevo proyecto de ley que reformaría los regímenes patrimoniales del matrimonio ${ }^{17}$, lo que en principio parecería significar el abandono definitivo de la tramitación del proyecto que ya se encontraba en el Congreso. El 5 de abril del presente año, transcurridos cinco meses desde el anuncio, se hizo efectiva la presentación del proyecto $^{18}$, referido únicamente al régimen de sociedad conyugal.

Frente a la presentación de este nuevo proyecto, y considerando la importancia e impacto que tiene el régimen de la sociedad conyugal, es necesario retomar seriamente la discusión en torno a la reforma de los regímenes patrimoniales del matrimonio. Si bien este tema va más allá del solo destino del régimen de sociedad conyugal, incluyéndose también en la discusión la posibilidad de la creación de un nuevo régimen de bienes y la reformulación del estatuto de los bienes familiares, por razones de extensión en este trabajo me limitaré únicamente a lo primero.

Me referiré, en primer lugar, al problema que se presenta en la administración de los bienes propios de la mujer, y a continuación, a lo que acontece respecto de los bienes sociales.

\section{El problema de los bienes propios de la mujer}

En Chile, la mujer alcanzó la plena capacidad de ejercicio en el año 1989, sin importar si se encuentra casada o no, y, en caso de que lo estuviese, sin consideración al régimen de bienes al que se encuentra sujeta ${ }^{19}$. Ello significó dejar atrás, al menos formalmente, la incapacidad relativa de la mujer casada bajo el régimen de sociedad conyugal. Formalmente, pues nuestro Código Civil conserva aún una regulación que no tiene coherencia alguna con la plena capacidad de la mujer.

Me refiero a las normas sobre administración de los bienes propios de la mujer casada bajo el comentado régimen, particularmente a los artículos 1749 y 1754, conforme a los cuales el marido, en su calidad de jefe de la sociedad conyugal, administra los bienes propios de la mujer, requiriendo de la autorización de esta última para realizar actos de disposición sobre dichos bienes. La única posibilidad que tiene la mujer de administrar sus propios bienes es mediante la autorización judicial ante la negativa o ausencia del marido ${ }^{20}$. En el caso del marido, éste no sufre ninguna limitación en la administración de sus bienes propios, por lo que no se vislumbra razón alguna para mantener la limitación para la mujer.

Esta regla ha sido fuertemente criticada por la doctrina nacional, pues si la mujer es plenamente capaz, no existe un motivo razonable para privarla de la administración de sus bienes propios ${ }^{21}$.

16 SERVICIO DE REGISTRO CIVIL E IDENTIFICACIÓN, Estadísticas con enfoque de género. [en línea] <http://www. registrocivil.cl/f_estadisticas_enfoque_de_genero.html> [consulta: 6 marzo 2011].

17 GOBIERNO modificará ley de sociedad conyugal para otorgar mayores atribuciones a la mujer. El Mercurio, Santiago, Chile, 25 de octubre de 2010. B-2; REFORMA a sociedad conyugal. El Mercurio, Santiago, Chile, 27 de octubre de 2010. A-2.

18 BOLETíN 7567-07. Modifica Código Civil y otras leyes, regulando el régimen patrimonial de sociedad conyugal. Fecha de ingreso: 5 de abril de 2011. [en línea] <http://sil.congreso.cl/pags/index.html> [consulta: 15 de abril de 2011].

19 LEY N 18.802 que modifica el Código Civil, el Código de Comercio y la Ley № 16.618. Diario Oficial 9 de junio de 1989, Santiago, Chile.

20 V. nota 10.

21 Así por ejemplo, DOMíNGUEZ A., Ramón. Reforma del Código Civil sobre situación jurídica de la mujer casada. Normas generales y sucesorales. Revista de Derecho Universidad de Concepción. № 184 (año LVI): 9. 1988; FIGUEROA 
El único fin que parece justificar tales limitaciones es la protección de la vivienda familiar, el cual está resguardado a través de la institución del bien familiar ${ }^{22}$, aplicable indistintamente a bienes inmuebles del marido o de la mujer, por lo que la limitación deviene en innecesaria.

Existe un consenso bastante extendido en la doctrina en cuanto a la arbitrariedad de la discriminación contenida en la norma. Incluso entre los académicos que estiman que la situación de la mujer casada en sociedad conyugal no es tan perjudicial como se afirma, encontramos a algunos dispuestos a conceder que conferir a la mujer la administración de sus bienes propios puede ser deseable ${ }^{23}$. Sin embargo, no parece haber despertado en nuestro país la resistencia que, en mi opinión, esta norma amerita.

Al revisar la evolución de la tramitación legislativa del primer proyecto de reforma citado en la primera sección de este trabajo ${ }^{24}$, se aprecia que en ningún estado de la tramitación la regla fue modificada. En efecto, de la lectura del proyecto en su última formulación se advierte que el cónyuge administrador de la sociedad conyugal administra tanto los bienes sociales como los propios del otro cónyuge (artículos 156-1 y 158-1) ${ }^{25}$. Ello parece, a lo menos, sorprendente, por cuanto la moción con que se presentó el proyecto de ley cuenta entre sus fundamentos la necesidad de igualar los derechos del marido y de la mujer ${ }^{26}$. La mencionada modificación fue propuesta por otros dos proyectos de ley, de los cuales el primero se encuentra archivado ${ }^{27}$, y el segundo, paralizado en su tramitación desde su ingreso en el año $2008^{28}$.

También resulta sorprendente el argumento que tiende a desechar la relevancia de la crítica sobre la base de que la existencia de estos bienes propios de la mujer tendría una supuesta incidencia estadística muy menor ${ }^{29}$, principalmente por dos razones.

Y., Gonzalo. Persona, pareja y familia. Santiago, Editorial Jurídica de Chile, 1995. P. 85-86; GÓMEZ DE LA TORRE Vargas, Maricruz. Situación de la mujer casada bajo sociedad conyugal y que se separa de hecho. Leyes y sentencias. № 69. 2008; RAMOS P., René. Derecho de familia, ciento cincuenta años después. Revista de Derecho Universidad de Concepción. No 219-220 (año LXXIV): 191. 2006; SCHMIDT H., Claudia. Los sistemas económicos del matrimonio. Gaceta Jurídica. № 182: 20. 1995; TAPIA R., Mauricio. Análisis crítico del proyecto de reforma de la sociedad conyugal y creación del régimen de comunidad de gananciales. [en línea] Boletín Microjuris N 199, $2007<$ http://cl.microjuris. com/login.jsp> [consulta: 6 marzo 2011], entre otros. Para Pablo Rodríguez, la razón es evidente: la administración del marido se justifica en el derecho legal de goce que tiene la sociedad conyugal sobre esos bienes. RODRíGUEZ G., Pablo. Innovaciones en materia de regímenes patrimoniales. Actualidad Jurídica. № 1: 193 y ss. 2000.

22 Artículo 141 y siguientes del Código Civil.

23 En este sentido, BARAONA G., Jorge. Problemas que presenta el proyecto que pretende modificar el régimen de sociedad conyugal. Leyes y sentencias. № 64. 2008; como también DOMíNGUEZ H., Carmen. La situación de la mujer casada en el régimen patrimonial chileno: mito o realidad. Revista Chilena de Derecho. Vol. 26 (1): 87-103. 1999. P. 100-101, aunque debe consignarse, por cierto, que la autora en referencia califica la crítica como "formal".

24 BOLETÍN 1707-18, op. cit., nota 7.

25 NUEVO PRIMER INFORME DE LA COMISIÓN DE CONSTITUCIÓN, LEGISLACIÓN, JUSTICIA Y REGLAMENTO, recaído en el proyecto de ley, en segundo trámite constitucional, que modifica el Código Civil y otras leyes complementarias en materia de sociedad conyugal o comunidad de gananciales, otorgando a la mujer y al marido iguales derechos y obligaciones. [en línea] <http://sil.congreso.cl/pags/index.html> [consulta: 10 diciembre 2010]

26 MOCIÓN DE LOS DIPUTADOS señorita Saa, señoras Prochelle, Rebolledo y Pollarolo, y señores Palma (don Andrés), Jocelyn-Holt, Balbontín y Pérez (don Aníbal). Modifica el Código Civil y leyes complementarias en materia de sociedad conyugal o comunidad de gananciales otorgando a la mujer y el marido iguales derechos y obligaciones (Boletín $N^{\circ}$ 1707-18) [en línea] <http://sil.congreso.cl/pags/index.html> [consulta: 10 diciembre 2010]

27 BOLETíN 1719-07. Modifica los artículos 1754, 1755, 1756 y 1757 del Código Civil, respecto a la administración, por parte de la mujer, de los bienes de la sociedad conyugal. Fecha de ingreso: 19 de octubre de 1995. [en línea] < http:// sil.congreso.cl/pags/index.html> [consulta: 10 diciembre 2010]

28 BOLETíN 5970-18. Introduce modificaciones a diversas disposiciones del Código Civil, consagrando el derecho de la mujer casada bajo el régimen de sociedad conyugal, de administrar los bienes propios que adquiera a título de herencia, legado o donación. Fecha de ingreso: 10 de julio de 2008. [en línea] < http://sil.congreso.cl/pags/index.html> [consulta: 10 diciembre 2010]

29 DOMíNGUEZ H., op. cit. nota 23, p. 101. 
En primer término, esta discusión nos ubica en el plano de los derechos fundamentales de las personas, particularmente la igualdad ante la ley y el derecho de propiedad. Si bien se trata de una regla de derecho privado, no es una regla de orden privado, quedando necesariamente sujetas a ella todas las mujeres que se casan bajo este régimen, sin posibilidad de alterarse por voluntad de los cónyuges. En este sentido, bastó un solo caso -el que se promovió ante la Comisión- para arriesgar la responsabilidad del Estado de Chile.

En segundo término, se trata de un argumento que subestima la situación actual de la vivienda en Chile. Conforme al último Censo $(2002)^{30}$, el 52,8\% de las viviendas pertenecen en propiedad a quienes las habitan, porcentaje que ha aumentado en los últimos ocho años ${ }^{31}$. Todos esos inmuebles son susceptibles de ser heredados, eventualmente, por una mujer casada en sociedad conyugal o por una mujer soltera que posteriormente se case bajo dicho régimen. Evidentemente, en la práctica, ello no ocurrirá en todos los casos, pero recordemos que el régimen de sociedad conyugal sigue siendo el predominante en nuestro país, y aunque su adopción es cada vez menor, el índice de viviendas propias va en aumento. De la combinación de ambos factores no es posible concluir, de manera obvia, que el número de mujeres que cuentan con bienes propios sea mínimo o se encamine necesariamente a la disminución.

En consecuencia, el problema de la administración de los bienes propios de la mujer casada en sociedad conyugal es un problema real y que demanda una mayor atención académica y política en orden a garantizar la igualdad entre marido y mujer. Es cierto que el nuevo proyecto de ley reformula la regla, atribuyendo a cada cónyuge la administración de sus bienes ${ }^{32}$. Pero ante la incertidumbre de lo que ocurrirá durante la tramitación del proyecto, debemos insistir en la relevancia de que la cuestión no sea pasada por alto por una supuesta irrelevancia, como lo fue en el proyecto anterior, y se incluya una regla tan simple como que cada cónyuge administre sus bienes propios, resguardando así su igualdad.

\section{El problema de los bienes sociales}

Distinto al anterior es el problema de la administración ordinaria de los bienes que conforman el haber de la sociedad conyugal, o bienes sociales.

En el régimen actual, conforme al artículo 1749 del Código Civil, el marido es el "jefe" de la sociedad conyugal, y como tal, administra los bienes sociales sujeto a una serie de limitaciones que la misma disposición establece y que consisten en la exigencia de autorización de la mujer para la realización de los actos más relevantes de administración.

Sin entrar a discutir los alcances y suficiencia de este sistema de limitaciones, lo cierto es que la asignación de la titularidad de la administración al marido resulta, en sí misma, arbitraria. No existe motivo razonable que fundamente una regla como la descrita, y la nomenclatura aún conservada por el Código Civil resulta, a lo menos, cuestionable. Cualquier sistema que determine imperativamente que la administración deba estar en un cónyuge determinado, adolecerá de este mismo defecto.

\footnotetext{
30 COMISIÓN NACIONAL DEL XVII CENSO DE POBLACIÓN Y VI DE VIVIENDA, Censo 2002, Síntesis de resultados. [en línea] <http://www.ine.cl/cd2002/sintesiscensal.pdf> [consulta: 6 marzo 2011]

31 Así lo permite concluir la última Encuesta CASEN, del año 2009, según la cual el 59,4\% de las familias nucleares cuenta con una vivienda dentro de sus activos. MINISTERIO DE PLANIFICACIÓN, Casen 2009, Encuesta de Caracterización Socioeconómica Nacional. [en línea] <http://www.mideplan.gob.cl/casen2009/RESULTADOS_CASEN_2009.pdf> [consulta: 6 marzo 2011]

32 BOLETíN 7567-07, op. cit. nota 18, Art. $1^{\circ} \mathrm{N}^{\circ} 16$.
} 
Mención aparte merece la institución del patrimonio reservado de la mujer casada en sociedad conyugal. Ideada como un mecanismo protector de la mujer que desarrolla una actividad remunerada, la institución termina por desequilibrar la balanza en perjuicio del marido: todo aquello que la mujer adquiere por medio de su trabajo independiente del marido es administrado por ella, sin limitaciones; todo aquello que el marido adquiere por medio de su trabajo queda sujeto a las limitaciones generales de la administración ordinaria de la sociedad conyugal.

La complejidad de las reglas de administración de los bienes sociales tiene una consecuencia práctica muy perjudicial para la mujer: generalmente, los terceros que contratan con una mujer casada en sociedad conyugal, ante la incertidumbre sobre la pertenencia de un bien al patrimonio administrado por el marido o al patrimonio reservado de dicha mujer, tienden a exigir indistintamente la comparecencia del marido, con el fin de protegerse de las reclamaciones que el marido podría realizar posteriormente. En consecuencia, el patrimonio reservado ni siquiera cumple eficazmente su primordial objetivo de otorgar a la mujer un espacio de libre administración de los bienes obtenidos con su trabajo, afectando de manera significativa su acceso al crédito y limitando sus posibilidades de celebrar toda clase de contratos. Esta exigencia práctica de comparecencia del marido, que en sí misma limita la libertad contractual de la mujer, resulta aún más problemática en casos como el de Sonia Arce, en que las mujeres se encuentran separadas de hecho de su marido y obtener su comparecencia puede resultar muy difícil o virtualmente imposible.

Sin duda la cuestión acá es mucho más compleja, pues la determinación de una adecuada regla de administración de los bienes sociales implica el equilibrio de dos principios diversos: por una parte, debe optarse por una regla que resguarde la igualdad entre los cónyuges, y por otra, que permita una administración eficiente de los bienes.

De entre las fórmulas posibles ${ }^{33}$, el primer proyecto de ley que hemos citado ${ }^{34}$ optó por una que podríamos llamar de "administración electiva": al comienzo del régimen, los cónyuges de común acuerdo determinan cuál de los dos será el administrador de la sociedad conyugal, y se genera un patrimonio reservado para quien no resulta designado administrador.

Esta opción es distinta de la fórmula presentada en la versión original del proyecto de ley, el $\mathrm{cual}^{35}$, proponía derechamente la eliminación de la sociedad conyugal y su sustitución por un régimen de participación en los gananciales en su variante de comunidad diferida (o "comunidad de gananciales", como el mismo proyecto lo denominó) ${ }^{36}$. Fueron las sucesivas modificaciones e indicaciones que se introdujeron al proyecto a lo largo de su tramitación las que lo llevaron a su estado actual: conservación del régimen de sociedad conyugal, con elección inicial de su administrador, el cual queda sujeto a limitaciones similares a las existentes actualmente en nuestra legislación ${ }^{37}$, y otorgamiento de un patrimonio reservado para el cónyuge no administrador. Paralelamente, se conservó el régimen de comunidad de gananciales, con carácter de régimen supletorio.

Esta misma fórmula fue adoptada por el nuevo proyecto de ley presentado en abril de este año por el Gobierno y que reforma el régimen de sociedad conyugal ${ }^{38}$.

\footnotetext{
33 Para una sinopsis de diversas fórmulas de administración de regímenes comunitarios, véase CORRAL T., Hernán, Alternativas de administración de bienes matrimoniales en el derecho comparado. Contribución al estudio de la reforma al régimen económico del matrimonio. Gaceta Jurídica. N N 340: 28 y ss. 2008.

34 BOLETÍN 1707-18, op. cit., nota 7.

35 MOCIÓN DE LOS DIPUTADOS, op. cit.

6 V. nota 1.

37 Arts. $156-1$ y $158-1$.

38 BOLETíN 7567-07, op. cit., nota 18, Art. $1^{\circ}$ № 43 a).
} 
Me parece cuestionable que un sistema como el descrito sea capaz de alcanzar el pretendido equilibrio entre cónyuges, principalmente por tres motivos. Primero, porque si bien pone en manos de los mismos cónyuges la elección del administrador, la operación del régimen sigue siendo desequilibrada, ubicando a uno de los cónyuges en una situación de poder respecto del otro. En efecto, tanto el antiguo como el nuevo proyecto de reforma declaran como uno de sus principios fundamentales el respeto a la igualdad de los cónyuges y, pese a dicha afirmación, introducen una regla que supone subordinar a uno de ellos a las decisiones del otro. Segundo, porque la regla expuesta deja en manos de los cónyuges la labor de revertir una práctica sistemática de discriminación en contra de la mujer, lo que en los hechos, probablemente, se traducirá en una constante réplica de la estructura legislativa actual. Y tercero, porque la conservación del patrimonio reservado para el cónyuge no administrador no hace sino mantener las asimetrías y dificultades presentes en el régimen actual.

En definitiva, parece ser más adecuada una fórmula que entregue a los cónyuges los mismos poderes durante la vigencia del régimen, como puede ser un sistema de administración conjunta, o bien de administración indistinta, siempre con un adecuado sistema de limitaciones que propendan a la protección del patrimonio familiar, sin perder la eficiencia en la gestión de los bienes. En este sentido, el nuevo proyecto de ley deja ver tímidamente una luz: establece que, a falta de la designación de un administrador por parte de los cónyuges, la administración de los bienes sociales se hará de manera conjunta ${ }^{39}$, requiriéndose el acuerdo expreso de ambos cónyuges para la realización de los actos más relevantes de administración, y presumiéndose el acuerdo en los demás actos cuando son realizados por uno solo de ellos ${ }^{40}$.

Finalmente, cabe mencionar un punto que también se incluye en el nuevo proyecto: la eliminación del haber relativo de la sociedad conyugal, pasando los bienes actualmente comprendidos en él, al patrimonio propio de cada cónyuge. Esta eliminación reduce al mínimo el ámbito de los bienes sociales gestionados por el cónyuge administrador. En los supuestos en que el cónyuge no administrador realice un trabajo remunerado y tenga, en consecuencia, su patrimonio reservado, el cónyuge administrador de la sociedad conyugal, en realidad, administrará principalmente sus bienes propios y el fruto de su propio trabajo. Lo que quiero hacer explícito con esta idea es que el nuevo proyecto reproduce el régimen de sociedad conyugal conservando su problema estructural de administración desequilibrada, y eliminando el que quizás sea el más destacable rasgo del régimen: su carácter comunitario, es decir, su aptitud para reflejar, durante la vigencia del régimen, la comunidad de vida que el matrimonio representa. Así, la sociedad conyugal se vuelve cada vez menos solidaria, y la calidad, más simbólica.

\section{El destino de la sociedad conyugal}

Que la sociedad conyugal necesita una urgente reforma resulta evidente. Al menos parece haber cierto consenso político respecto de este punto. Nuestra preocupación, entonces, ha de ser el contenido específico de esta reforma.

Habrá quienes promoverán la eliminación radical de este tradicional régimen y su reemplazo por uno nuevo, y otros que buscarán su mantención. Para quienes defiendan su permanencia, los cambios serán más o menos radicales, lo que en algún momento hará que nos preguntemos qué queda de la sociedad conyugal y por qué conservamos su nombre.

39 Ibid, b).

40 Ibíd, h). 
Sea que se reemplace o se conserve, me parece que el objetivo central de esta esperada reforma debe ser la construcción de un régimen que sea capaz de representar la comunidad de vida que implica el matrimonio y a la vez respete la igualdad de los cónyuges. Éste es el tipo de régimen que hace falta en nuestro sistema.

En este sentido, los regímenes de participación en los gananciales resultan insuficientes; la solidaridad se presenta sólo al momento del término del régimen, pero durante su vigencia, no logran reflejar esa comunidad: no hay un patrimonio común. Por su parte, la sociedad conyugal reformada en el sentido propuesto por los dos proyectos de comentados conserva una distribución desequilibrada de los poderes de los cónyuges que, en mi opinión, no se legitima por el sólo hecho de que sean ellos quienes decidan quién será el administrador.

La fórmula para alcanzar una solución conveniente no es novedosa y ya la anunciaba el profesor FUEYO hace más de 25 años. Ésta debe conjugar tres factores en dosis adecuadas, sin sobrevalorar ninguno de ellos: la unidad o comunidad de intereses, la personalidad individual de los cónyuges y el interés legítimo de terceros ${ }^{41}$.

La sociedad conyugal resulta problemática, hoy en día, porque para muchos parece sobredimensionar "la unidad o comunidad de intereses" en perjuicio de la personalidad individual de los cónyuges. En mi opinión, no conjuga adecuadamente ninguno de éstos. Difícil es hablar de una comunidad de intereses si la existencia del patrimonio reservado y la posibilidad de renunciar a los gananciales otorgan a la mujer la posibilidad de desligarse casi completamente de esta comunidad si no le resulta económicamente conveniente. Más difícil aún es hablar de personalidad individual si se desconoce a la mujer la capacidad para administrar sus bienes propios y se asigna imperativamente la gestión de los sociales al marido.

Personalmente, estimo que estos factores se conjugan de mejor manera en un régimen de comunidad administrada indistintamente por los cónyuges, con ciertas limitaciones para resguardar la integridad y estabilidad familiar, radicando la administración de los bienes propios de los cónyuges en su dueño y sin otorgar beneficios especiales a ninguno de ellos, tales como el patrimonio reservado o la posibilidad de renunciar a los gananciales.

En definitiva, en la medida en que seamos capaces de convertir a la sociedad conyugal en un régimen que logre articular estos elementos de manera equilibrada, estaremos otorgando a las personas la posibilidad de acceder a un régimen que refleja la comunidad familiar y resguarda la igualdad de sus miembros. En caso contrario, el Estado de Chile arriesga su responsabilidad ante las instancias internacionales correspondientes, y la sociedad conyugal, a la larga y conforme evolucione la sociedad, estará destinada a desaparecer.

41 FUEYO L., Fernando. Problemática general del régimen patrimonial del matrimonio. Gaceta Jurídica. № 53: 7-8. 1984. 